\title{
Phase II study of dovitinib in patients with metastatic and/or unresectable gastrointestinal stromal tumours after failure of imatinib and sunitinib
}

\author{
Y-K Kang *,1, C Yoo ${ }^{1}$, B-Y Ryoo ${ }^{1}$, J J Lee ${ }^{1}$, E Tan ${ }^{2}$, I Park ${ }^{1}$, J H Park ${ }^{1}$, Y J Choi ${ }^{1}$, J Jo ${ }^{1}$, J-S Ryu ${ }^{1}$ and M-H Ryu ${ }^{1}$ \\ ${ }^{1}$ Department of Oncology and Nuclear Medicine, Asan Medical Center, University of Ulsan College of Medicine, Seoul, Korea and \\ ${ }^{2}$ Oncology Clinical Pharmacology, Novartis Pharmaceuticals Corporation, Florham Park, NJ, USA
}

Background: This prospective, phase II trial evaluated the efficacy and safety of dovitinib in patients with metastatic and/or unresectable gastrointestinal stromal tumours (GISTs) after failure of at least imatinib and sunitinib.

Methods: Patients received oral dovitinib, $500 \mathrm{mg}$ once daily, for 5 consecutive days, followed by a 2-day rest, every 28 days. The primary endpoint was disease control rate (DCR; objective response + stable disease (SD)) at 24 weeks, assessed by computed tomography (CT) scan according to RECIST v1.0. Metabolic response was evaluated by positron emission tomography (PET)-CT scans performed at baseline and after 4 weeks of treatment.

Results: Between September 2011 and April 2012, 30 patients were enroled. DCR at 24 weeks by RECIST v1.0 was 13\% and one patient (3\%) had a partial response. Based on the European Organization for Research and Treatment of Cancer PET response criteria, four patients (13\%) had a metabolic partial response after 4 weeks of treatment. At a median follow-up of 8.3 months (range, 6.3-12.2 months), median progression-free survival (PFS) was 3.6 months ( $95 \%$ confidence interval (Cl), 3.5-3.7 months) and median overall survival was 9.7 months $(95 \% \mathrm{Cl}, 6.0-13.4$ months). Metabolic progressive disease at Week 4 was significantly associated with shorter PFS ( $P=0.03)$. Grade $3 / 4$ adverse events included asthenia $(20 \%)$, neutropenia $(13 \%)$, thrombocytopenia $(10 \%)$, and hypertriglyceridaemia (10\%). Most toxicities were manageable by dose modification.

Conclusion: Dovitinib showed modest antitumour activity with manageable toxicities in heavily pretreated patients with advanced GISTs.

Gastrointestinal stromal tumours (GISTs) are the most common mesenchymal tumours of the digestive tract (Nilsson et al, 2005). Most GISTs harbour activating mutations of the gene encoding KIT or platelet-derived growth factor receptor (PDGFR) $\alpha$, resulting in the constitutive activation of protein tyrosine kinase signalling (Lasota and Miettinen, 2008). Imatinib has improved survival outcomes dramatically and has become the standard firstline treatment for advanced GISTs (Demetri et al, 2002; Blanke et al, 2008). Patients who become resistant to imatinib are treated with second-line sunitinib (Demetri et al, 2006). Eventually, however, most patients become resistant to both imatinib and sunitinib, necessitating new salvage treatments (Gramza et al, 2009). Although many new targeted agents have been studied in patients with advanced GISTs (Demetri, 2011), at the time of study initiation, no therapeutic option after failure of both imatinib and sunitinib had been approved (Europe Sarcoma Network Working

*Correspondence: Professor Y-K Kang; E-mail: ykkang@amc.seoul.kr

This study was presented in part at the 2012 ESMO meeting, 29 September-2 October 2012, in Vienna, Austria.

Received 10 June 2013; revised 27 August 2013; accepted 9 September 2013; published online 1 October 2013

(C) 2013 Cancer Research UK. All rights reserved 0007-0920/13 
Group, 2012; Kang et al, 2012; National Comprehensive Cancer Network, 2012).

Dovitinib (TKI258) is a novel multikinase inhibitor targeting vascular endothelial growth factor receptors (VEGFRs) 1-3, fibroblast growth factor receptors (FGFRs) 1-3, fetal liver tyrosine kinase receptor 3, PDGFR $\beta$, and KIT (Lee et al, 2005). Dovitinib showed potent antitumour activity in various tumour xenograft models (Lee et al, 2005). Furthermore, a phase I trial of dovitinib in a cohort that included two patients with GISTs resulted in disease control for 8 months in one patient, where both imatinib and sorafenib failed (Sarker et al, 2008). Based on these findings and the target profile of dovitinib, we conducted a phase II trial evaluating the efficacy and safety of dovitinib in patients with GISTs refractory or intolerant to both imatinib and sunitinib.

\section{MATERIALS AND METHODS}

This was an open-label, single-arm, phase II study. The protocol was approved by the institutional review board of Asan Medical Center, Seoul, Korea, and all patients provided written informed consent before enrolment. This study was conducted in accordance with the Declaration of Helsinki and Good Clinical Practice.

Eligibility. Patients with histologically and molecularly confirmed metastatic and/or unresectable GIST were considered eligible. Inclusion criteria included the following: age $\geqslant 20$ years; resistance and/or intolerance to both imatinib and sunitinib (previous use of other tyrosine kinase inhibitors (TKIs) or chemotherapy was permitted); an Eastern Cooperative Oncology Group (ECOG) performance status of $0-2$; resolution of all toxicities of prior treatments to grade $0-1$ per Common Terminology Criteria for Adverse Events (CTCAE) 3.0; measurable lesion per RECIST 1.0 (Therasse et al, 2000); and adequate bone marrow, hepatic, and renal function. Patients were also required to have a life expectancy of $\geqslant 12$ weeks, with study entry preceded by a washout period of previous TKIs for more than four times the half-life. Except for sunitinib and regorafenib, patients who received other TKIs targeting VEGFR or FGFR were not permitted to enrol. Patients were excluded if they had a serious medical condition that was clinically significant or required active intervention.

Study treatment. Dovitinib was administered at $500 \mathrm{mg}$ orally once daily for 5 consecutive days, followed by a 2-day rest, with each cycle consisting of 28 days (Angevin et al, 2013). Study treatment was discontinued if patients had disease progression, unacceptable toxicities, or withdrew consent. Doses were modified based on the worst grade of toxicity according to the protocol, but doses less than $300 \mathrm{mg}$ per day were not allowed. Patients who interrupted treatment for more than 21 days were discontinued.

Efficacy and safety assessment. Baseline assessments included medical history, physical examination, complete blood count, serum chemistry with electrolytes, coagulation battery, urinalysis, electrocardiography, cardiac enzymes, chest X-ray, computed tomography (CT) scan, and fusion 18-fluorodeoxyglucose (FDG)-positron emission tomography (PET)-CT scan. Computed tomography scans were performed after 4 and 8 weeks of treatment and every 8 weeks thereafter. Response was assessed by investigators using RECIST 1.0 (Therasse et al, 2000). To assess metabolic responses, PET-CT scans were performed at baseline and after 4 weeks of treatment. Maximum standardised uptake values $\left(\mathrm{SUV}_{\max }\right)$ of all tumour lesions were combined and averaged (average $S U V_{\max }$ ) for each patient. Metabolic response was defined based on the PET response criteria of the European Organization for Research and Treatment of Cancer (EORTC) (Young et al, 1999); a metabolic partial response (mPR) was defined as a $>25 \%$ reduction in average $\mathrm{SUV}_{\text {max }}$; metabolic stable disease
$(\mathrm{mSD})$ between a $25 \%$ decrease and $25 \%$ increase in average $\mathrm{SUV}_{\text {max }}$; metabolic progressive disease ( $\mathrm{mPD}$ ) as a $\geqslant 25 \%$ increase in average $S_{U V}$ max or the appearance of new FDG uptake in metastatic lesions. Toxicity was graded by CTCAE 3.0.

Pharmacokinetic evaluation. Blood samples were collected 1, 3, 6, and $24 \mathrm{~h}$ following the $500 \mathrm{mg}$ oral dose of dovitinib on Week 1 , Day 1 , and before dosing and $1,3,6$, and $24 \mathrm{~h}$ after dosing on Week 4, Day 5. The plasma concentrations of dovitinib were measured by liquid chromatography-tandem mass spectrometry, and analysed using Phoenix software (Pharsight Inc., Mountain View, CA, USA) to determine pharmacokinetic parameters including area under the concentration-time curve (AUC), time $\left(T_{\max }\right)$ to reach the maximum plasma concentration $\left(C_{\max }\right)$, and trough plasma concentration $\left(C_{\min }\right)$.

Statistical analysis. The primary endpoint of this study was disease control rate (DCR), defined as the proportion of patients showing an objective response and stable disease (SD), at 24 weeks of study treatment. Secondary endpoints included progression-free survival (PFS), overall survival (OS), and overall response rate by CT or PET-CT scan.

Based on the Fleming rule, this study was designed to detect an improvement in DCR at 24 weeks of $20 \%$ from a null rate of $6 \%$ with type I (one-sided) and II errors of $10 \%$. Assuming that $20 \%$ of patients were lost to follow-up, a total of 30 patients were required. If four or more patients achieved DCR at 24 weeks, the null hypothesis would be rejected with a target error rate of $10 \%$.

Progression-free survival was defined as the time from the date of first dose to the date of disease progression or death, whichever occurred first. The OS was defined from the date of first dose to the date of death. The probability of survival was estimated by the Kaplan-Meier method, and the log-rank test was used to compare survival curves. A $P$-value $<0.05$ was considered statistically significant, and all analyses were performed using SPSS 18.0 (SPSS Inc., Chicago, IL, USA).

\section{RESULTS}

Patient characteristics. Between September 2011 and April 2012, a total of 30 patients with metastatic and/or unresectable GISTs who had treatment failure with imatinib and sunitinib were enroled. Baseline patient characteristics are summarised in Table 1. Median age was 57.5 years (range, 35-76 years) and 21 (70\%) patients were male. All patients had distant metastases. Median number of prior TKI regimens was two (range, 2-5); 13 patients (43\%) received and had treatment failure with nilotinib (27\%), regorafenib (7\%), or both $(10 \%)$ before dovitinib treatment. KIT exon 11 and 9 mutations were detected in 20 (71\%) and 5 (18\%) patients, respectively. Resistance to imatinib and sunitinib per RECIST criteria was documented in all and 28 (93\%) patients, respectively; the remaining two patients were intolerant to sunitinib.

Efficacy. DCR at 24 weeks, the primary end point, was 13\% (95\% confidence interval (CI), 4.7-30.3\%). At Week 24 of dovitinib treatment, 4 patients had disease stabilisation, 23 had disease progression or were dead, and 3 were not available for assessment: 2 due to early loss to follow-up and 1 due to patient refusal. According to RECIST criteria, 1 patient (3\%) achieved partial response (PR), resulting in an objective response rate of $3 \%, 21$ (70\%) had SD for at least 8 weeks, and $6(20 \%)$ showed progressive disease (PD), whereas $2(7 \%)$ were not evaluable owing to the early loss to follow-up (Table 2). Median change from baseline in the sum of longest tumour diameters was $7 \%$ (interquartile range (IQR), -5-18\%; Figure 1A). Eight patients experienced a 


\begin{tabular}{|c|c|}
\hline Characteristics & Overall $(n=30)$ \\
\hline Sex, male & $21(70 \%)$ \\
\hline Age (years), median (range) & $57.5(35-76)$ \\
\hline \multicolumn{2}{|l|}{ ECOG performance status } \\
\hline $0-1$ & $24(80 \%)$ \\
\hline $2-3$ & \\
\hline \multicolumn{2}{|l|}{ Primary site } \\
\hline $\begin{array}{l}\text { Stomach } \\
\text { Small bowel } \\
\text { Others }\end{array}$ & $\begin{aligned} 8 & (27 \%) \\
20 & (67 \%) \\
2 & (7 \%)\end{aligned}$ \\
\hline \multicolumn{2}{|l|}{ Metastatic site } \\
\hline $\begin{array}{l}\text { Any } \\
\text { Peritoneum } \\
\text { Liver } \\
\text { Lung } \\
\text { Bone }\end{array}$ & $\begin{array}{c}30 \text { (100\%) } \\
22 \text { (73\%) } \\
20 \text { (67\%) } \\
4(13 \%) \\
4(13 \%)\end{array}$ \\
\hline \multicolumn{2}{|l|}{ Kinase mutation $(n=28)$} \\
\hline $\begin{array}{l}\text { KIT exon } 11 \\
\text { KIT exon } 9 \\
\text { PDGFRA exon } 18 \\
\text { Wild type }\end{array}$ & $\begin{aligned} & 20(71 \%) \\
& 5(18 \%) \\
& 1(4 \%) \\
& 2(7 \%)\end{aligned}$ \\
\hline \multicolumn{2}{|c|}{ Documented disease progression on prior TKIs } \\
\hline $\begin{array}{l}\text { Imatinib } \\
\text { Sunitinib }\end{array}$ & $\begin{array}{l}30(100 \%) \\
28(93 \%)\end{array}$ \\
\hline TTP at imatinib $400 \mathrm{mg}$ per day, median (range) & 20.4 months (3.0-71.2) \\
\hline TTP at sunitinib, median (range) & 7.1 months $(2.1-41.6)$ \\
\hline \multicolumn{2}{|l|}{ Previous TKIs as third or more line therapy } \\
\hline $\begin{array}{l}\text { Nilotinib } \\
\text { Regorafenib } \\
\text { Both nilotinib and regorafenib }\end{array}$ & $\begin{array}{l}8(27 \%) \\
2(7 \%) \\
3(10 \%)\end{array}$ \\
\hline \multicolumn{2}{|c|}{$\begin{array}{l}\text { Abbreviations: } E C O G=\text { Eastern Cooperative Oncology Group; PDGFRA = platelet-derivec } \\
\text { growth factor receptor } \alpha \text {; TKI = tyrosine kinase inhibitor; TTP }=\text { time to progression. } \\
{ }^{a} \text { No mutations in } K I T \text { exons } 11,9,13 \text {, and } 17 \text {, and PDGFRA exons } 12 \text { and } 18 .\end{array}$} \\
\hline
\end{tabular}

Table 2. Best response by RECIST 1.0 and metabolic response by PET

\begin{tabular}{|c|c|}
\hline RECIST v1.0 & Total $\left(\mathbf{n}=30^{a}\right)$ \\
\hline Partial response & $1(3 \%)$ \\
\hline Stable disease ${ }^{\mathbf{b}}$ & $21(70 \%)$ \\
\hline Progressive disease & $6(20 \%)$ \\
\hline Metabolic response by PET & Total $\left(n=30^{\mathrm{a}}\right)$ \\
\hline Partial response & $4(13 \%)$ \\
\hline Stable disease & $15(50 \%)$ \\
\hline Progressive disease & $9(30 \%)$ \\
\hline \multicolumn{2}{|c|}{$\begin{array}{l}\text { Abbreviation: PET = positron emission tomography. } \\
a_{\text {Two patients were not evaluable due to early loss to follow-up. }} \\
\mathrm{b}_{\text {Sustained for } 8 \text { weeks or more. }}\end{array}$} \\
\hline
\end{tabular}

decrease in tumour diameter with a median of $-11 \%$ (IQR, $-16 \%$ to $-7 \%)$.

Of the 28 patients whose metabolic responses were assessable, $4(13 \%)$ achieved mPR, $15(50 \%)$ achieved $\mathrm{mSD}$, and $9(30 \%)$
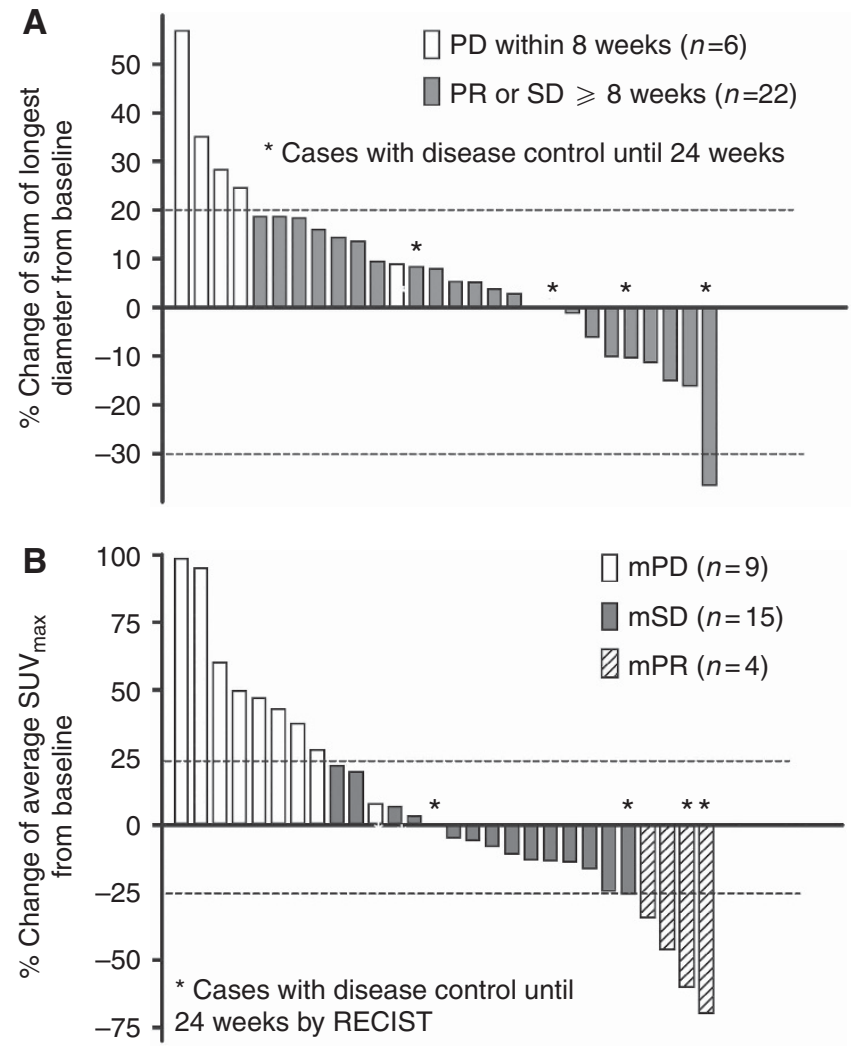

Figure 1. Waterfall plots of best per cent change in the sum of the longest tumour diameter by CT scan (A) and average $S_{\text {U }}$ max of all tumour lesions by PET scan (B). Abbreviations: $\mathrm{mPD}=$ metabolic progressive disease; $\mathrm{mPR}=$ metabolic partial response; $\mathrm{mSD}=$ metabolic stable disease; $\mathrm{PD}=$ progressive disease; $\mathrm{PR}=$ partial response; $\mathrm{SD}=$ stable disease.

had mPD. After 4 weeks of treatment with dovitinib, the median change in average $\mathrm{SUV}_{\max }$ was $-3 \%$ from baseline (IQR, - 16-36\%), with 14 patients (47\%) showing a decrease in average $\mathrm{SUV}_{\max }$ of a median $-15 \%$ (IQR, $-38 \%$ to $-11 \%$; Figure 1B).

Figure 2 shows the CT and PET-CT scan images of a patient who achieved PR and MPR with dovitinib. This patient had a KIT exon 9 mutation and received dovitinib after progression on 12 months of imatinib and 3.5 months of sunitinib. Tumour SUV was substantially reduced at 4 weeks in PET-CT scan, indicating $\mathrm{mPR}$, and PR according to RECIST criteria was confirmed after 28 weeks of treatment. At the time of analysis, this patient had received dovitinib without progression for approximately 11 months.

At a median follow-up of 8.3 months (range, 6.3-12.2 months), the median PFS was 3.6 months (95\% CI, 3.5-3.7 months) and the 6-month PFS rate was $13 \%$ (Figure 3 ). The median OS was 9.7 months (95\% CI, 6.0-13.4 months). Subgroup analyses showed that median PFS was significantly worse in patients with $\mathrm{mPD}$ after 4 weeks of dovitinib than in patients with $\mathrm{mPR}$ or $\mathrm{mSD}$ (2.8 months (95\% CI, 0.7-4.9 months) vs 4.2 months (95\% CI, 2.5-5.9), hazard ratio 2.7 (95\% CI, 1.1-6.6); $P=0.03$ ), despite there being no significant between-group differences in baseline characteristics. Progression-free survival did not differ by primary genotype (KIT exon 11 mutations $v s$ other mutations, $P=0.71$ ), age $(<60 v s \geqslant 60, P=0.77)$, sex $(P=0.21)$, ECOG performance status $(0-1 v s 2, P=0.50)$, number of prior TKI regimens $(2 v s \geqslant 3$, $P=0.88)$, previous treatment with nilotinib $(P=0.96)$ or regorafenib $(P=0.10)$, and the best response $(\mathrm{CR} / \mathrm{PR} v s \mathrm{SD} / \mathrm{PD})$ and time to progression ( $<$ median $v s \geqslant$ median) to previous imatinib 

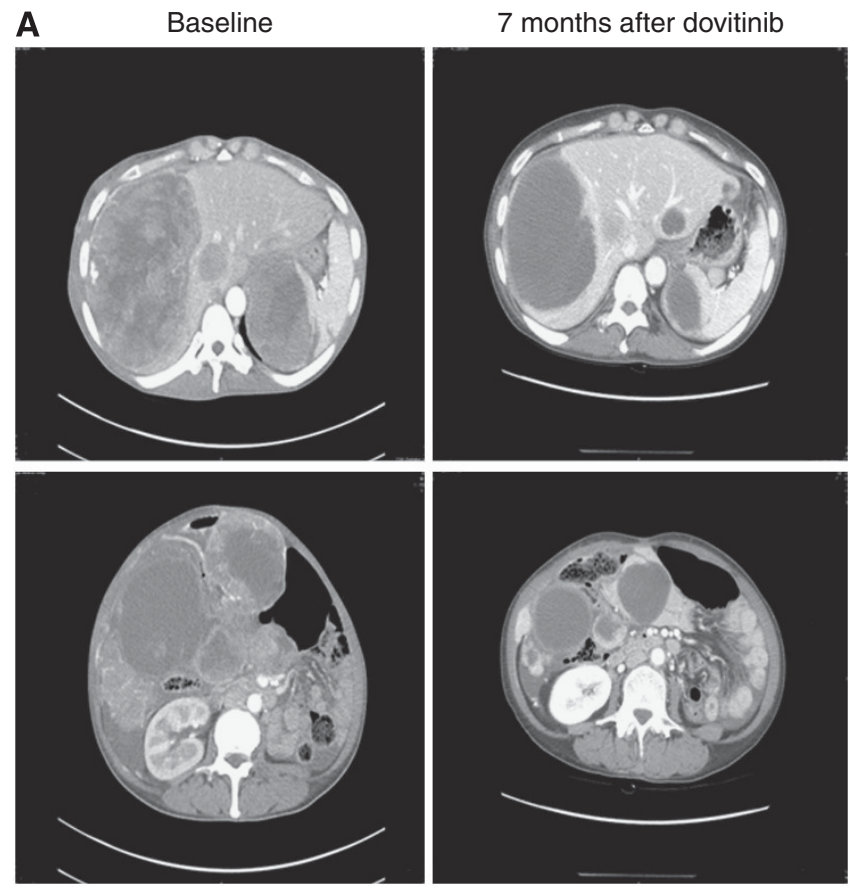

B
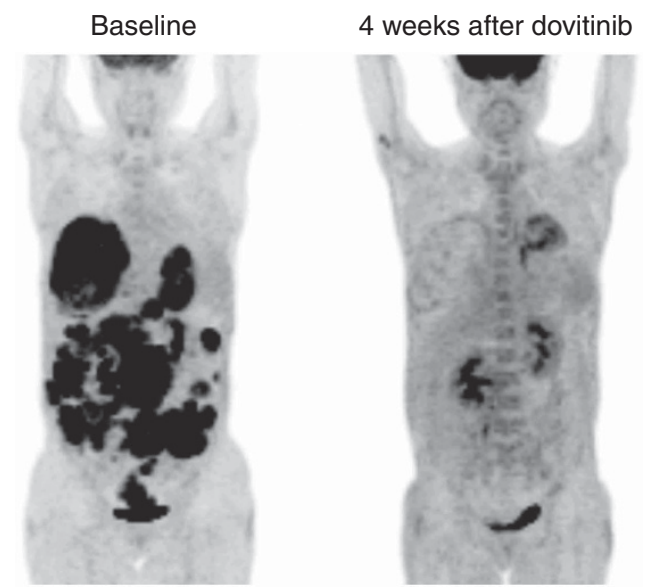

Figure 2. CT (A) and PET (B) scan images of patients who achieved objective response.

( $P=0.68$ and $P=0.26$, respectively) or sunitinib $(P=0.80$ and $P=0.32$, respectively) treatment.

Safety. The most common adverse events (AEs) of any grade were diarrhoea (63\%), nausea (60\%), asthenia (60\%), elevated alanine aminotransferase (50\%), and anaemia (50\%). These AEs were generally mild and tolerable. Grade 3/4 AEs included asthenia (20\%), neutropenia (13\%), thrombocytopenia (10\%), and hypertriglyceridaemia (10\%), with most cases being manageable by dose modification. There were no treatment-related deaths. Table 3 summarises AEs occurring in $10 \%$ or more patients. Dovitinib was discontinued owing to toxicity in two patients: one for grade 3 QTc prolongation after four cycles, and the other one for grade 3 asthenia after five cycles. One patient experienced life-threatening severe AEs, including grade 3 left ventricular dysfunction, grade 4 thrombocytopenia, and grade 3 QTc prolongation. In total, 7 of 30 (23\%) patients required dose reductions based on protocol-defined toxicities, with doses reduced to $300 \mathrm{mg}$ per day in three patients $(10 \%)$. Reasons for dose reduction included neutropenia $(n=3)$, thrombocytopenia $(n=2)$, vomiting $(n=1)$, and hypertriglyceridaemia $(n=1)$. There was one patient whose dose reduced to
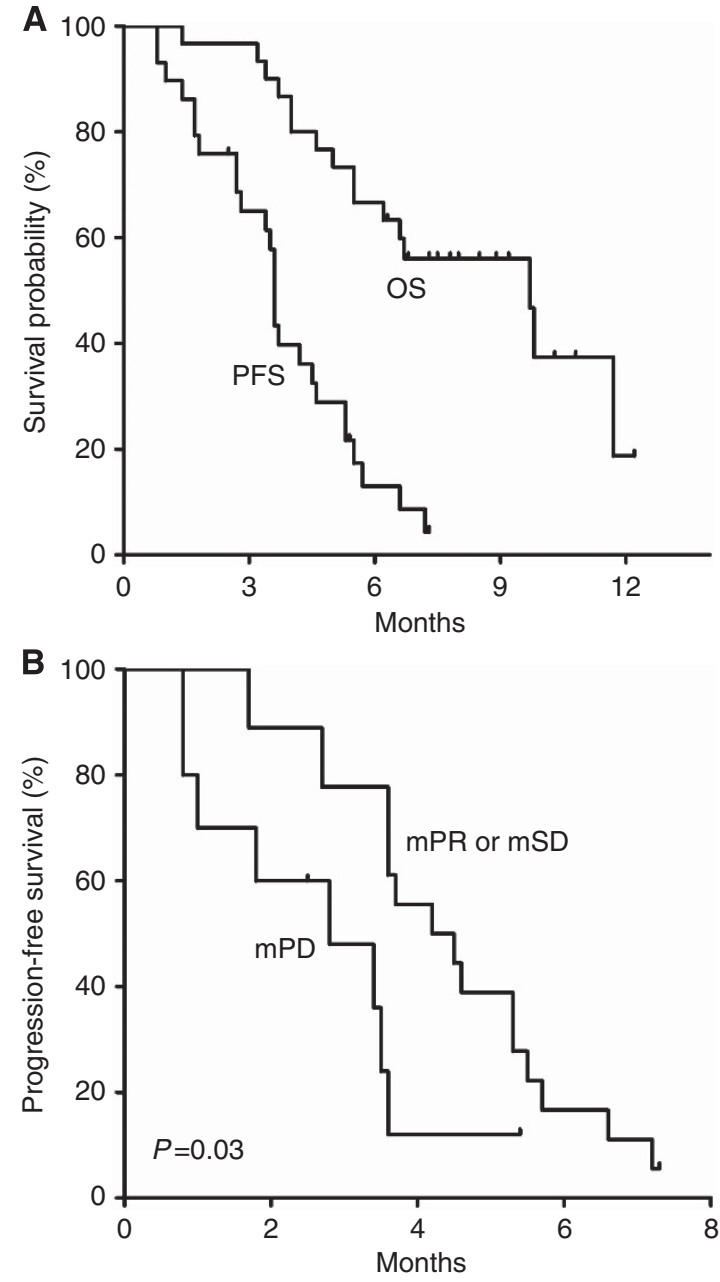

Figure 3. Survival outcomes (A) and PFS by metabolic response after 4 weeks of dovitinib treatment (B). In panel A, median PFS was 3.6 months (95\% Cl, 3.5-3.7) and median OS was 9.7 months $(95 \% \mathrm{Cl}$, 6.0-13.4). In panel B, median PFS was 2.8 months (95\% Cl, 0.7-4.9) in patients with $\mathrm{mPD}$ and 4.2 months $(95 \% \mathrm{Cl}, 2.5-5.9 ; P=0.03)$ in patients with $\mathrm{mPR}$ or $\mathrm{mSD}$. Abbreviations: $\mathrm{mPD}=$ metabolic progressive disease; $\mathrm{mPR}=$ metabolic partial response; $\mathrm{mSD}=$ metabolic stable disease; OS $=$ overall survival; $\mathrm{PFS}=$ progression-free survival.

$400 \mathrm{mg}$ per day due to grade 3 neutropenia, but tolerated subsequent re-escalation to $500 \mathrm{mg}$ per day.

Pharmacokinetics. Dovitinib pharmacokinetics was evaluated in 14 patients, 11 males, and three females, of mean body weight $62 \mathrm{~kg}$, with 10 having mild to moderate renal dysfunction. Pharmacokinetic parameters and plasma concentration-time profiles are shown in Supplementary Table S1 and Supplementary Figure S1, respectively. The mean $C_{\max }$ and AUC of dovitinib were $194 \pm 51 \mathrm{ng} \mathrm{ml}^{-1}$ and $3444 \pm 847 \mathrm{~h}^{\star} \mathrm{ng} \mathrm{ml}^{-1}$, respectively, on Week 1 , Day 1 and were $232 \pm 84 \mathrm{ng} \mathrm{ml}^{-1}$ and $4396 \pm 1712 \mathrm{~h}^{\star} \mathrm{ng} \mathrm{ml}^{-1}$, respectively, on Week 4, Day 5. Large interindividual variability (CV\%) was observed in the parameters. There were no relationships between AUC and covariates, such as age $(P=0.72)$, sex $(P=0.36)$, body weight $(P=0.36)$, body surface area $(P=0.46)$, and estimated glomerular filtration rate $(P=0.32)$.

\section{DISCUSSION}

In this phase II study, we investigated the efficacy and safety of dovitinib in patients with advanced GISTs. Dovitinib was well 


\begin{tabular}{|c|c|c|c|c|}
\hline & \multicolumn{4}{|c|}{ Total $(n=30)$} \\
\hline Adverse events & Grade 1 & Grade 2 & Grade 3 & Grade 4 \\
\hline Neutropenia $^{a}$ & $5(20 \%)$ & $2(7 \%)$ & $3(10 \%)$ & $1(3 \%)$ \\
\hline Anaemia & $10(33 \%)$ & $4(13 \%)$ & $1(3 \%)$ & $0(0 \%)$ \\
\hline Thrombocytopenia & $10(33 \%)$ & $0(0 \%)$ & $1(3 \%)$ & $2(7 \%)$ \\
\hline Anorexia & $6(20 \%)$ & $4(13 \%)$ & $0(0 \%)$ & $0(0 \%)$ \\
\hline Nausea & 17 (57\%) & $1(3 \%)$ & $0(0 \%)$ & $0(0 \%)$ \\
\hline Vomiting & $9(30 \%)$ & $2(7 \%)$ & $1(3 \%)$ & $0(0 \%)$ \\
\hline Dyspepsia & $5(17 \%)$ & $6(20 \%)$ & $0(0 \%)$ & $0(0 \%)$ \\
\hline Stomatitis & $2(7 \%)$ & $5(17 \%)$ & $0(0 \%)$ & $0(0 \%)$ \\
\hline Diarrhoea & $14(47 \%)$ & $3(10 \%)$ & $2(7 \%)$ & $0(0 \%)$ \\
\hline Asthenia & $9(30 \%)$ & $3(10 \%)$ & $6(20 \%)$ & $0(0 \%)$ \\
\hline Skin rash & 7 (23\%) & $2(7 \%)$ & $0(0 \%)$ & $0(0 \%)$ \\
\hline Elevation of AST & $10(33 \%)$ & $2(7 \%)$ & $0(0 \%)$ & $0(0 \%)$ \\
\hline Elevation of ALT & $12(40 \%)$ & $2(7 \%)$ & $1(3 \%)$ & $0(0 \%)$ \\
\hline Hyperbilirubinaemia & $2(7 \%)$ & $1(3 \%)$ & $0(0 \%)$ & $0(0 \%)$ \\
\hline Increased creatinine & $3(10 \%)$ & $2(7 \%)$ & $0(0 \%)$ & $0(0 \%)$ \\
\hline Hypertriglyceridaemia & $4(13 \%)$ & $1(3 \%)$ & $3(10 \%)$ & $0(0 \%)$ \\
\hline Hypertension & 7 (23\%) & $4(13 \%)$ & $2(7 \%)$ & $0(0 \%)$ \\
\hline Proteinuria & $3(10 \%)$ & $6(20 \%)$ & $1(3 \%)$ & $0(0 \%)$ \\
\hline Headache & $5(17 \%)$ & $1(3 \%)$ & $0(0 \%)$ & $0(0 \%)$ \\
\hline Abdominal pain & $6(20 \%)$ & $6(20 \%)$ & $0(0 \%)$ & $0(0 \%)$ \\
\hline
\end{tabular}

tolerated and showed modest antitumour activity in these heavily pretreated patients. This study met the prespecified primary end point of a DCR of $13 \%$ over 24 weeks, although only one (3\%) patient achieved PR according to RECIST. The median PFS and OS were 3.6 and 9.7 months, respectively. Furthermore, treatment with dovitinib reduced the metabolic activity of GISTs in $\sim 47 \%$ of patients, with $13 \%$ of patients achieving mPR. As about half of our patients received dovitinib as fourth- or fifth-line therapy, these results suggest that dovitinib is clinically active in patients with GIST.

Imatinib has revolutionised the treatment of advanced GISTs (Demetri et al, 2002; Blanke et al, 2008). However, most patients develop resistance to and clinical progression on imatinib due to the development of secondary KIT mutations (Antonescu et al, 2005; Heinrich et al, 2006; Gramza et al, 2009). Most of these acquired mutations occur in the regions of the KIT gene that encode the ATP/drug-binding pocket (exons 13 and 14) and the activation loop (exon 17) (Antonescu et al, 2005; Heinrich et al, 2006; Wardelmann et al, 2006). Sunitinib is approved as the second-line therapy for GISTs after failure of imatinib, with a median PFS of about 7 months in a phase III trial (Demetri et al, 2006). Sunitinib potently inhibits imatinib-resistant KIT exon 13 and 14 mutations, but has little activity against imatinib-resistant KIT exon 17 mutations (Heinrich et al, 2008; Nishida et al, 2009; Heinrich et al, 2012). Although sunitinib inhibits VEGFR as well as KIT and PDGFR, it is still unclear whether VEGFR inhibition contributed to the activity of sunitinib against imatinib-resistant GISTs (Heinrich et al, 2012).

Because patients eventually progress on imatinib and sunitinib, and their prognosis is generally poor, many targeted agents have been investigated in this setting, including nilotinib (Montemurro et al, 2009; Kim et al, 2011; Sawaki et al, 2011; Reichardt et al, 2012), sorafenib (Wiebe et al, 2008; Montemurro et al, 2012; Park et al, 2012), regorafenib (George et al, 2012; Demetri et al, 2013), vatalanib (Joensuu et al, 2011), dasatinib (Trent et al, 2011), IPI-504 (Demetri et al, 2010), and BIIB021 (Dickson et al, 2013). Nilotinib has a chemical structure and target profile similar to imatinib and has been widely investigated in patients with GISTs (Montemurro et al, 2009; Kim et al, 2011; Sawaki et al, 2011; Reichardt et al, 2012). In a recent phase III trial for patients with prior failure of at least imatinib and sunitinib, nilotinib achieved a median PFS of 3.6 months and a DCR at 24 weeks of $7.3 \%$ and, when the efficacy of nilotinib was compared with control arm in true third-line patient population with exclusion of patients who received more than two prior agents and those without welldocumented progression on second-line therapy, nilotinib provided significantly longer OS. However, it failed to demonstrate a significant improvement in survival in the intention-to-treat population (Reichardt et al, 2012). Sorafenib, a multikinase inhibitor that blocks KIT, PDGFR, and VEGFR, showed promising activity as salvage therapy after failure of standard regimens for GIST patients with median PFS of 4.6-6.4 months in previous phase II and retrospective studies (Wiebe et al, 2008; Montemurro et al, 2012; Park et al, 2012) and DCR at 24 weeks, presented in a phase II study (Park et al, 2012), was 36\%. Regorafenib is a highly related compound of sorafenib, with a similar target profile. Based on the promising activity, DCR at 16 weeks of $79 \%$ and median PFS of 10.0 months, in a phase II trial (George et al, 2012), regorafenib was compared with placebo as third-line therapy in a randomised phase III trial (Demetri et al, 2013). Regorafenib enhanced median PFS relative to placebo (4.8 vs 0.9 months), with a 12 -week DCR in the regorafenib group 53\%, although objective responses were rarely observed (Demetri et al, 2013). Regorafenib is therefore approved as third-line treatment, following failures of imatinib and sunitinib, in patients with GISTs. Regorafenib and sorafenib may act in imatinib/sunitinib-resistant GISTs by potently inhibiting imatinib-resistant secondary KIT mutations involving the activation loop as these mutations are generally resistant to sunitinib (Heinrich et al, 2008; Nishida et al, 2009; George et al, 2012; Heinrich et al, 2012). Because the mechanisms of resistance to TKIs in GISTs are heterogeneous and multiple acquired mutations can occur in a single patient (Wardelmann et al, 2006), KIT kinase inhibitors may have limited effectiveness in GISTs highly refractory to TKIs, with the activity of each inhibitor depending on the sensitivity to specific mutations. Therefore, inhibiting HSP90 has been considered a novel strategy to overcome this obstacle. Although several HSP90 inhibitors have been tested in clinical trials, further investigations are necessary to establish the role of HSP90 inhibition in GISTs (Demetri et al, 2010; Dickson et al, 2013).

Despite successful results in phase III trial, regorafenib prolongs PFS for only several months, indicating unmet medical needs for GIST patients refractory to multiple TKIs. Therefore, further clinical trials of new drugs are necessary, based on understanding the mechanisms of tumour resistance to TKIs. We found that dovitinib had modest activity against TKI-resistant GISTs. As 43\% of our study cohort previously received nilotinib or regorafenib, the efficacy outcomes of dovitinib seem promising, encouraging its further clinical development in this indication. However, the target of dovitinib for clinical activity in GISTs remains unclear and further preclinical studies of dovitinib activity against primary and secondary KIT mutations are needed to understand its efficacy in TKI-resistant GISTs. Although dovitinib targets VEGFR and FGFR, the significance of VEGFR inhibition in GISTs after imatinib failure remains unknown (Heinrich et al, 2012), and little is known about the role of the FGF pathway in treatment of GISTs. To address this issue, we are now conducting a correlative study of 
plasma protein biomarkers and plasma-based KIT mutations in this study cohort.

The dosing schedule of dovitinib tested in this study was tolerable and toxicities were generally mild. Most grade 3/4 toxicities were manageable by dose modification or supportive care, with only two patients discontinuing study treatment owing to toxicities. The dovitinib toxicities observed in this study were in line with those in patients with other types of cancer (Sarker et al, 2008; Andre et al, 2011; Kim et al, 2011; Angevin et al, 2013), with asthenia being the most common grade $3 / 4 \mathrm{AE}$ (20\% in the present study vs $15-27 \%$ in previous studies). In contrast with the rare haematological toxicities observed in previous trials (Sarker et al, 2008; Kim et al, 2011; Angevin et al, 2013), 10\% of our patients experienced grade $3 / 4$ neutropenia and thrombocytopenia, although there were no complications.

Interim PET assessment after 4 weeks of treatment was found to predict PFS in these patients. Our findings agree with previous results, showing that PET is a sensitive tool to assess metabolic response to therapy in GISTs (Prior et al, 2009). Furthermore, conventional tumour-size-based response criteria may have intrinsic limitations in patients with GIST, which may underestimate the benefits of TKIs (Benjamin et al, 2007; Reichardt et al, 2012). The use of PET in addition to conventional imaging may be helpful in differentiating 'true progression' or 'true response', especially in GIST patients with multiple lesions who progressed after several lines of treatment.

In line with previous results (Kim et al, 2011; Wang et al, 2013), we observed large interindividual variations in dovitinib exposure. As expected, exposure to dovitinib, as assessed by AUC, was about $28 \%$ higher on Week 4, Day 5 than on Week 1, Day 1 owing to drug accumulation resulting from multiple doses. Previous studies suggest that dovitinib exposure may be dependent on body weight, sex, renal dysfunction, and ethnicity (Wang et al, 2013). Although all of our patients were Asian with low body weight (mean $62 \mathrm{~kg}$ ), and $71 \%$ had impaired renal function, which may be associated with greater drug exposure (Wang et al, 2013), the $C_{\max }$ and AUC of dovitinib in this study were consistent with those in patients with melanoma (Kim et al, 2011) and even lower than those of patients with renal cell carcinoma (Angevin et al, 2013). Furthermore, we could not find any relationship between these potential covariates and dovitinib exposure in our patients. As the studies analysing pharmacokinetics of dovitinib, including ours, have all involved small sample size, these findings may be premature. Further efforts should be made to find the covariates affecting the blood level of dovitinib, and the relationship between dovitinib exposure and efficacy. These may be necessary for more effective clinical development of dovitinib.

In summary, dovitinib, a novel multikinase inhibitor that primarily targets VEGFR, FGFR, and KIT, showed modest antitumour activity in heavily pretreated patients with advanced GISTs. As this study reached its primary endpoint, further investigations of dovitinib are warranted in GIST patients.

\section{ACKNOWLEDGEMENTS}

This research was funded in part by Norvartis Pharmaceuticals. The authors thank the research nurses, Chang Suk Lee, Mo Yeol Beck, and Jaehee Lee, for their assistance with this study.

\section{CONFLICT OF INTEREST}

Yoon-Koo Kang has received honorarium, a research grant, and is a consultant for Novartis and Bayer. Eugene Tan is an employee of Novartis. All other authors declare no conflict of interest.

\section{REFERENCES}

Andre F, Bachelot T, Campone M, Dalenc F, Perez-Garcia J, Hurvitz S, Turner N, Rugo H, Shi M, Zhang Y (2011) A multicenter, open-label phase II trial of dovitinib, an FGFR1 inhibitor, in FGFR1 amplified and non-amplified metastatic breast cancer. J Clin Oncol 29(Suppl): abstract 508.

Angevin E, Lopez-Martin J, Lin CC, Gschwend JE, Harzstark A, Castellano D, Soria JC, Sen P, Chang J, Shi MM, Kay A, Escudier B (2013) Phase I study of dovitinib (TKI258), an oral FGFR, VEGFR, and PDGFR inhibitor, in advanced or metastatic renal cell carcinoma. Clin Cancer Res 19: 1257-1268.

Antonescu CR, Besmer P, Guo T, Arkun K, Hom G, Koryotowski B, Leversha MA, Jeffrey PD, Desantis D, Singer S, Brennan MF, Maki RG, DeMatteo RP (2005) Acquired resistance to imatinib in gastrointestinal stromal tumor occurs through secondary gene mutation. Clin Cancer Res 11(11): 4182-4190.

Benjamin RS, Choi H, Macapinlac HA, Burgess MA, Patel SR, Chen LL, Podoloff DA, Charnsangavej C (2007) We should desist using RECIST, at least in GIST. J Clin Oncol 25(13): 1760-1764.

Blanke CD, Demetri GD, von Mehren M, Heinrich MC, Eisenberg B, Fletcher JA, Corless CL, Fletcher CD, Roberts PJ, Heinz D, Wehre E, Nikolova Z, Joensuu H (2008) Long-term results from a randomized phase II trial of standard- versus higher-dose imatinib mesylate for patients with unresectable or metastatic gastrointestinal stromal tumors expressing KIT. J Clin Oncol 26(4): 620-625.

Demetri G, Le Cesne A, Von Mehren M, Chmielowski B, Bauer S, Chow W, Rodenas E, McKee K, Grayzel D, Kang YK (2010) Final results from a phase III study of IPI-504 (retaspimycin hydrochloride) versus placebo in patients (pts) with gastrointestinal stromal tumors (GIST) following failure of kinase inhibitor therapies. ASCO Gastrointest Cancers Symp Meet Abstr 28(15_suppl): 64 .

Demetri GD (2011) Differential properties of current tyrosine kinase inhibitors in gastrointestinal stromal tumors. Semin Oncol 38(Suppl 1): S10-S19.

Demetri GD, Reichardt P, Kang YK, Blay JY, Rutkowski P, Gelderblom H, Hohenberger P, Leahy M, von Mehren M, Joensuu H, Badalamenti G, Blackstein M, Le Cesne A, Schoffski P, Maki RG, Bauer S, Nguyen BB, Xu J, Nishida T, Chung J, Kappeler C, Kuss I, Laurent D, Casali PG (2013) Efficacy and safety of regorafenib for advanced gastrointestinal stromal tumours after failure of imatinib and sunitinib (GRID): an international, multicentre, randomised, placebo-controlled, phase 3 trial. Lancet 381(9863): 295-302.

Demetri GD, van Oosterom AT, Garrett CR, Blackstein ME, Shah MH, Verweij J, McArthur G, Judson IR, Heinrich MC, Morgan JA, Desai J, Fletcher CD, George S, Bello CL, Huang X, Baum CM, Casali PG (2006) Efficacy and safety of sunitinib in patients with advanced gastrointestinal stromal tumour after failure of imatinib: a randomised controlled trial. Lancet 368(9544): 1329-1338.

Demetri GD, von Mehren M, Blanke CD, Van den Abbeele AD, Eisenberg B, Roberts PJ, Heinrich MC, Tuveson DA, Singer S, Janicek M, Fletcher JA, Silverman SG, Silberman SL, Capdeville R, Kiese B, Peng B, Dimitrijevic S, Druker BJ, Corless C, Fletcher CD, Joensuu H (2002) Efficacy and safety of imatinib mesylate in advanced gastrointestinal stromal tumors. $N$ Engl $J$ Med 347(7): 472-480.

Dickson MA, Okuno SH, Keohan ML, Maki RG, D’Adamo DR, Akhurst TJ, Antonescu CR, Schwartz GK (2013) Phase II study of the HSP90-inhibitor BIIB021 in gastrointestinal stromal tumors. Ann Oncol 24(1): 252-257.

Europe Sarcoma Network Working Group (2012) Gastrointestinal stromal tumors: ESMO Clinical Practice Guidelines for diagnosis, treatment and follow-up. Ann Oncol 23(Suppl 7): vii49-vii55.

George S, Wang Q, Heinrich MC, Corless CL, Zhu M, Butrynski JE, Morgan JA, Wagner AJ, Choy E, Tap WD, Yap JT, Van den Abbeele AD, Manola JB, Solomon SM, Fletcher JA, von Mehren M, Demetri GD (2012) Efficacy and safety of regorafenib in patients with metastatic and/or unresectable GI stromal tumor after failure of imatinib and sunitinib: a multicenter phase II trial. J Clin Oncol 30(19): 2401-2407.

Gramza AW, Corless CL, Heinrich MC (2009) Resistance to tyrosine kinase inhibitors in gastrointestinal stromal tumors. Clin Cancer Res 15(24): 7510-7518.

Heinrich MC, Corless CL, Blanke CD, Demetri GD, Joensuu H, Roberts PJ, Eisenberg BL, von Mehren M, Fletcher CD, Sandau K, McDougall K, 
Ou WB, Chen CJ, Fletcher JA (2006) Molecular correlates of imatinib resistance in gastrointestinal stromal tumors. J Clin Oncol 24(29): 4764-4774.

Heinrich MC, Maki RG, Corless CL, Antonescu CR, Harlow A, Griffith D, Town A, McKinley A, Ou WB, Fletcher JA, Fletcher CD, Huang X, Cohen DP, Baum CM, Demetri GD (2008) Primary and secondary kinase genotypes correlate with the biological and clinical activity of sunitinib in imatinib-resistant gastrointestinal stromal tumor. J Clin Oncol 26(33): 5352-5359.

Heinrich MC, Marino-Enriquez A, Presnell A, Donsky RS, Griffith DJ, McKinley A, Patterson J, Taguchi T, Liang CW, Fletcher JA (2012) Sorafenib inhibits many kinase mutations associated with drug-resistant gastrointestinal stromal tumors. Mol Cancer Ther 11(8): 1770-1780.

Joensuu H, De Braud F, Grignagni G, De Pas T, Spitalieri G, Coco P, Spreafico C, Boselli S, Toffalorio F, Bono P, Jalava T, Kappeler C, Aglietta M, Laurent D, Casali PG (2011) Vatalanib for metastatic gastrointestinal stromal tumour (GIST) resistant to imatinib: final results of a phase II study. Br J Cancer 104(11): 1686-1690.

Kang YK, Kang HJ, Kim KM, Sohn T, Choi D, Ryu MH, Kim WH, Yang HK (2012) Clinical practice guideline for accurate diagnosis and effective treatment of gastrointestinal stromal tumor in Korea. Cancer Res Treat 44(2): 85-96.

Kim KB, Chesney J, Robinson D, Gardner H, Shi MM, Kirkwood JM (2011) Phase I/II and pharmacodynamic study of dovitinib (TKI258), an inhibitor of fibroblast growth factor receptors and VEGF receptors, in patients with advanced melanoma. Clin Cancer Res 17(23): 7451-7461.

Lasota J, Miettinen M (2008) Clinical significance of oncogenic KIT and PDGFRA mutations in gastrointestinal stromal tumours. Histopathology 53(3): 245-266

Lee SH, Lopes de Menezes D, Vora J, Harris A, Ye H, Nordahl L, Garrett E, Samara E, Aukerman SL, Gelb AB, Heise C (2005) In vivo target modulation and biological activity of CHIR-258, a multitargeted growth factor receptor kinase inhibitor, in colon cancer models. Clin Cancer Res 11(10): 3633-3641.

Montemurro M, Gelderblom H, Bitz U, Schutte J, Blay JY, Joensuu H, Trent J, Bauer S, Rutkowski P, Duffaud F, Pink D (2012) Sorafenib as third- or fourth-line treatment of advanced gastrointestinal stromal tumour and pretreatment including both imatinib and sunitinib, and nilotinib: a retrospective analysis. Eur J Cancer 49(5): 1027-1031.

Montemurro M, Schoffski P, Reichardt P, Gelderblom H, Schutte J, Hartmann JT, von Moos R, Seddon B, Joensuu H, Wendtner CM, Weber E, Grunwald V, Roth A, Leyvraz S (2009) Nilotinib in the treatment of advanced gastrointestinal stromal tumours resistant to both imatinib and sunitinib. Eur J Cancer 45(13): 2293-2297.

National Comprehensive Cancer Network (2012) NCCN Clinical Practice Guidelines in Oncology Soft Tissue Sarcoma (Version 3.2012). Accessed February 2013; http://www.nccn.org/professionals/ physician_gls/pdf/sarcoma.pdf.

Nilsson B, Bumming P, Meis-Kindblom JM, Oden A, Dortok A, Gustavsson B, Sablinska K, Kindblom LG (2005) Gastrointestinal stromal tumors: the incidence, prevalence, clinical course, and prognostication in the preimatinib mesylate era-a population-based study in western Sweden. Cancer 103(4): 821-829.

Nishida T, Takahashi T, Nishitani A, Doi T, Shirao K, Komatsu Y, Nakajima K, Hirota S (2009) Sunitinib-resistant gastrointestinal stromal tumors harbor cis-mutations in the activation loop of the KIT gene. Int J Clin Oncol 14(2): 143-149.

Park SH, Ryu MH, Ryoo BY, Im SA, Kwon HC, Lee SS, Park SR, Kang BY, Kang YK (2012) Sorafenib in patients with metastatic gastrointestinal stromal tumors who failed two or more prior tyrosine kinase inhibitors: a phase II study of Korean gastrointestinal stromal tumors study group. Invest New Drugs 30(6): 2377-2383.

Prior JO, Montemurro M, Orcurto MV, Michielin O, Luthi F, Benhattar J, Guillou L, Elsig V, Stupp R, Delaloye AB, Leyvraz S (2009) Early prediction of response to sunitinib after imatinib failure by $18 \mathrm{~F}-$ fluorodeoxyglucose positron emission tomography in patients with gastrointestinal stromal tumor. J Clin Oncol 27(3): 439-445.

Reichardt P, Blay JY, Gelderblom H, Schlemmer M, Demetri GD, Bui-Nguyen B, McArthur GA, Yazji S, Hsu Y, Galetic I, Rutkowski P (2012) Phase III study of nilotinib versus best supportive care with or without a TKI in patients with gastrointestinal stromal tumors resistant to or intolerant of imatinib and sunitinib. Ann Oncol 23(7): 1680-1687.

Sarker D, Molife R, Evans TR, Hardie M, Marriott C, Butzberger-Zimmerli P, Morrison R, Fox JA, Heise C, Louie S, Aziz N, Garzon F, Michelson G, Judson IR, Jadayel D, Braendle E, de Bono JS (2008) A phase I pharmacokinetic and pharmacodynamic study of TKI258, an oral, multitargeted receptor tyrosine kinase inhibitor in patients with advanced solid tumors. Clin Cancer Res 14(7): 2075-2081.

Sawaki A, Nishida T, Doi T, Yamada Y, Komatsu Y, Kanda T, Kakeji Y, Onozawa Y, Yamasaki M, Ohtsu A (2011) Phase 2 study of nilotinib as third-line therapy for patients with gastrointestinal stromal tumor. Cancer 117(20): 4633-4641.

Therasse P, Arbuck SG, Eisenhauer EA, Wanders J, Kaplan RS, Rubinstein L, Verweij J, Van Glabbeke M, van Oosterom AT, Christian MC, Gwyther SG (2000) New guidelines to evaluate the response to treatment in solid tumors. European Organization for Research and Treatment of Cancer, National Cancer Institute of the United States, National Cancer Institute of Canada. J Natl Cancer Inst 92(3): 205-216.

Trent J, Wathen K, Von Mehren M, Samuels B, Staddon A, Choy E, Butrynski J, Chugh R, Chow W, Rushing D (2011) A phase II study of dasatinib for patients with imatinib-resistant gastrointestinal stromal tumor (GIST). J Clin Oncol 29(Suppl): abstract 10006.

Wang X, Kay A, Anak O, Angevin E, Escudier B, Zhou W, Feng Y, Dugan M, Schran H (2013) Population pharmacokinetic/pharmacodynamic modeling to assist dosing schedule selection for dovitinib. J Clin Pharmacol 53(1): 14-20.

Wardelmann E, Merkelbach-Bruse S, Pauls K, Thomas N, Schildhaus HU, Heinicke T, Speidel N, Pietsch T, Buettner R, Pink D, Reichardt P, Hohenberger P (2006) Polyclonal evolution of multiple secondary KIT mutations in gastrointestinal stromal tumors under treatment with imatinib mesylate. Clin Cancer Res 12(6): 1743-1749.

Wiebe L, Kasza K, Maki R, D’Adamo D, Chow W, Wade J, Agamah E, Stadler W, Vokes E, Kindler H (2008) Activity of sorafenib (SOR) in patients (pts) with imatinib (IM) and sunitinib (SU)-resistant (RES) gastrointestinal stromal tumors (GIST): a phase II trial of the University of Chicago Phase II Consortium. J Clin Oncol 26(Suppl): abstract 10502.

Young H, Baum R, Cremerius U, Herholz K, Hoekstra O, Lammertsma AA, Pruim J, Price P (1999) Measurement of clinical and subclinical tumour response using $[18 \mathrm{~F}]$-fluorodeoxyglucose and positron emission tomography: review and 1999 EORTC recommendations. European Organization for Research and Treatment of Cancer (EORTC) PET Study Group. Eur J Cancer 35(13): 1773-1782.

This work is published under the standard license to publish agreement. After 12 months the work will become freely available and the license terms will switch to a Creative Commons AttributionNonCommercial-Share Alike 3.0 Unported License.

Supplementary Information accompanies this paper on British Journal of Cancer website (http://www.nature.com/bjc) 